\title{
ANÁLISIS CRíTICO DE LA RESTAURACIÓN DE LA CASA DE OSAMBELA, 1981, LIMA
}

\author{
CRITICAL ANALYSIS OF THE RESTORATION \\ OF THE HOUSE OF OSAMBELA, 1981, LIMA
}

MARTHA VÁSQUEZ GUTIÉRREZ ${ }^{(\star)}$

Fecha de recepción: 31 de agosto de 2017

Fecha de aprobación: 02 de diciembre de 2017

\section{RESUMEN}

En 1981, se realizó en la Casa de Osambela un proyecto de restauración integral que tuvo en aquellos años un impacto positivo en la comunidad limeña, pues allí se generó, gracias a su nuevo uso como Centro Cultural Inca Garcilaso de la Vega, un espacio de interacción social e intercambio cultural que afianzó la identidad cultural de los limeños de esa época. Por ello, es trascendente analizar los planteamientos teóricos y metodológicos que se emplearon para dar forma al proyecto de restauración y de asignación de nuevos usos de esta notable edificación, y cómo estos se relacionan con los criterios teóricos de restauración entonces establecidos en los documentos internacionales para la protección del patrimonio inmueble. A través del análisis crítico, se busca reconocer los aportes y carencias de esta intervención restaurativa, y cómo esta contribuyó a la conservación y revaloración del patrimonio cultural inmueble.

\section{PALABRAS CLAVE}

Casa de Osambela, restauración, patrimonio inmueble

\section{ABSTRACT}

In 1981, a comprehensive restoration project was carried out at the Casa de Osambela. It had, in those years, a positive impact on the Lima community because, thanks to its new use as the Inca Garcilaso de la Vega Cultural Center, it fostered a space of social interaction and cultural exchange that strengthened the cultural identity of those citizens of Lima. Thus, it is important to analyze the theoretical and methodological aspects that were employed in the project of restoring and assigning new uses to this remarkable building, and how those relate to the theoretical criteria of restoration for the protection of immovable heritage established in international documents. Through critical analysis, we seek to recognize the contributions and shortcomings of this restorative intervention, and how it contributed to the preservation and revaluation of immovable cultural heritage.

\section{KEYWORDS}

House of Osambela, restoration, immovable heritage

(*) Este análisis crítico se centra en el caso peruano del previo estudio comparativo de casos de intervención restaurativa, entre la Casa de Osambela (Perú) y la Casona de Puerta Castillo (España), del curso de Metodología de la Intervención en el Patrimonio Inmueble de la Maestría en Gestión del Patrimonio Cultural de la Universidad Nacional Mayor de San Marcos (UNMSM), en el semestre II-2016.

${ }^{(* *)}$ Licenciada en Arqueología de la UNMSM, con estudios en la Maestría de Gestión del Patrimonio Cultural de la Unidad de Posgrado de Ciencia Sociales de la misma universidad. Trabaja como arqueóloga en la UNMSM. Contacto: marel.vasgu@gmail.com 
devenir Vol. 5, Nº, ENERO - JUNIO 2018, PP. 77-98 - ESTUDIOS | ISSN 2312-7562 | E-ISSN 2616-4949

UNIVERSIDAD NACIONAL DE INGENIERÍA, LIMA

Convento de santo Domingo

UBICACION : Casa Oquendo

(01)
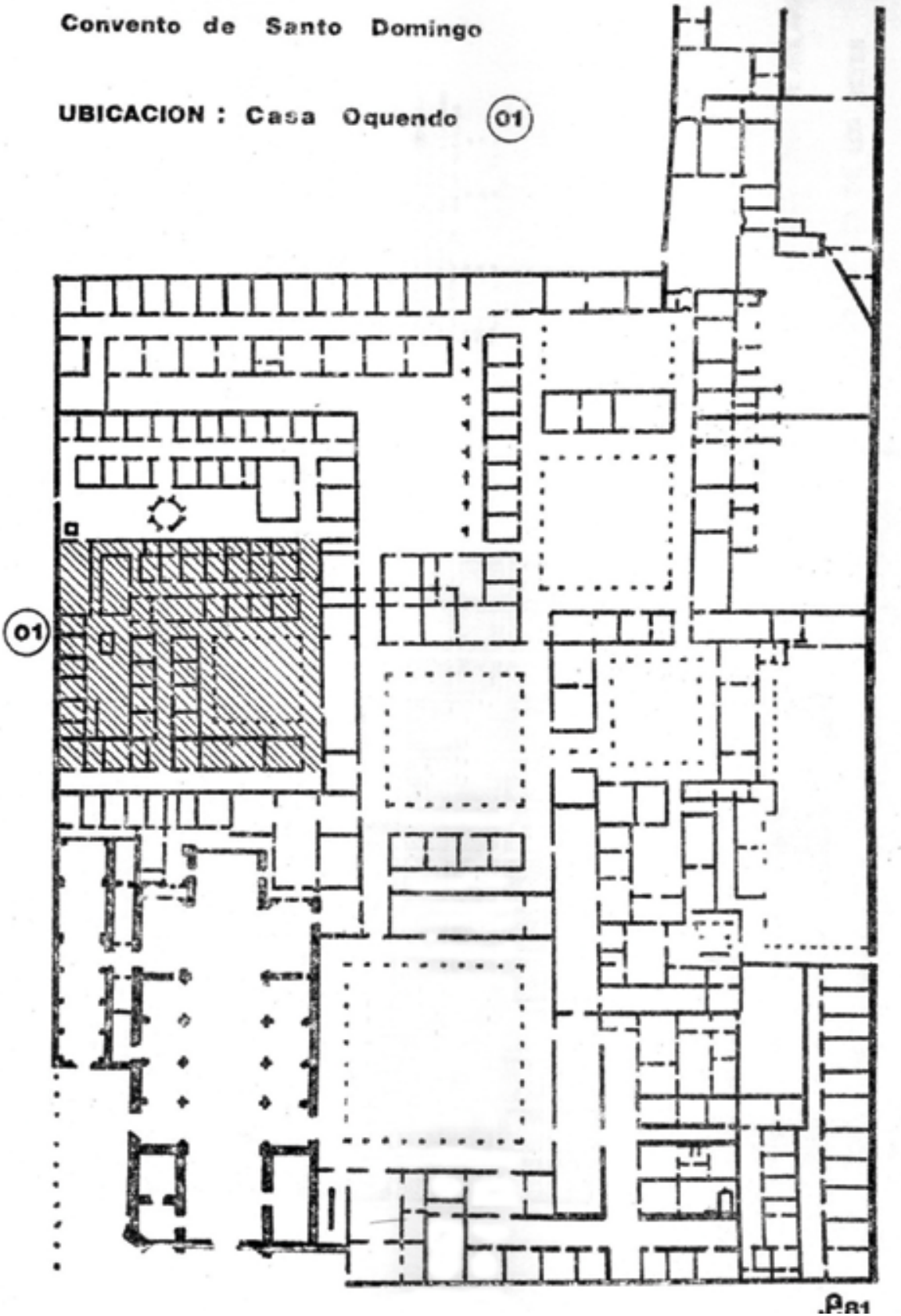

Figura 1. Ubicación de la Casa de Osambela.

En Boletín N 14 Centro de Investigación y Restauración de Bienes Monumentales, por I. Flores, p. 81, Lima, 1981.
La Casa de Osambela, también conocida como Palacio de Osambela o Palacio de Oquendo, constituye una de las edificaciones más notables de Lima, por sus características arquitectónicas, muy particulares, que pueden ser apreciadas aún en la actualidad. Está ubicada en Jr. Conde de Superunda 298, en el Centro Histórico de Lima. Cuenta con un área de terreno de 1,235.25 $\mathrm{m}^{2}$, un área construida de 1,111.95 $\mathrm{m}^{2}$ y un área techada de 2,361.32 $\mathrm{m}^{2}$. Fue declarada Patrimonio Cultural de la Nación en el año 1972 y Patrimonio de la Humanidad en 1991 por la UNESCO.

Su construcción data de comienzos del s. XIX, pero el área donde se erigió este edificio tendría antecedentes de ocupación precolonial que se remontan al periodo Desarrollo Regionales (200-600 d. C.), como sugiere la evidencia arqueológica -una ofrenda- en- 


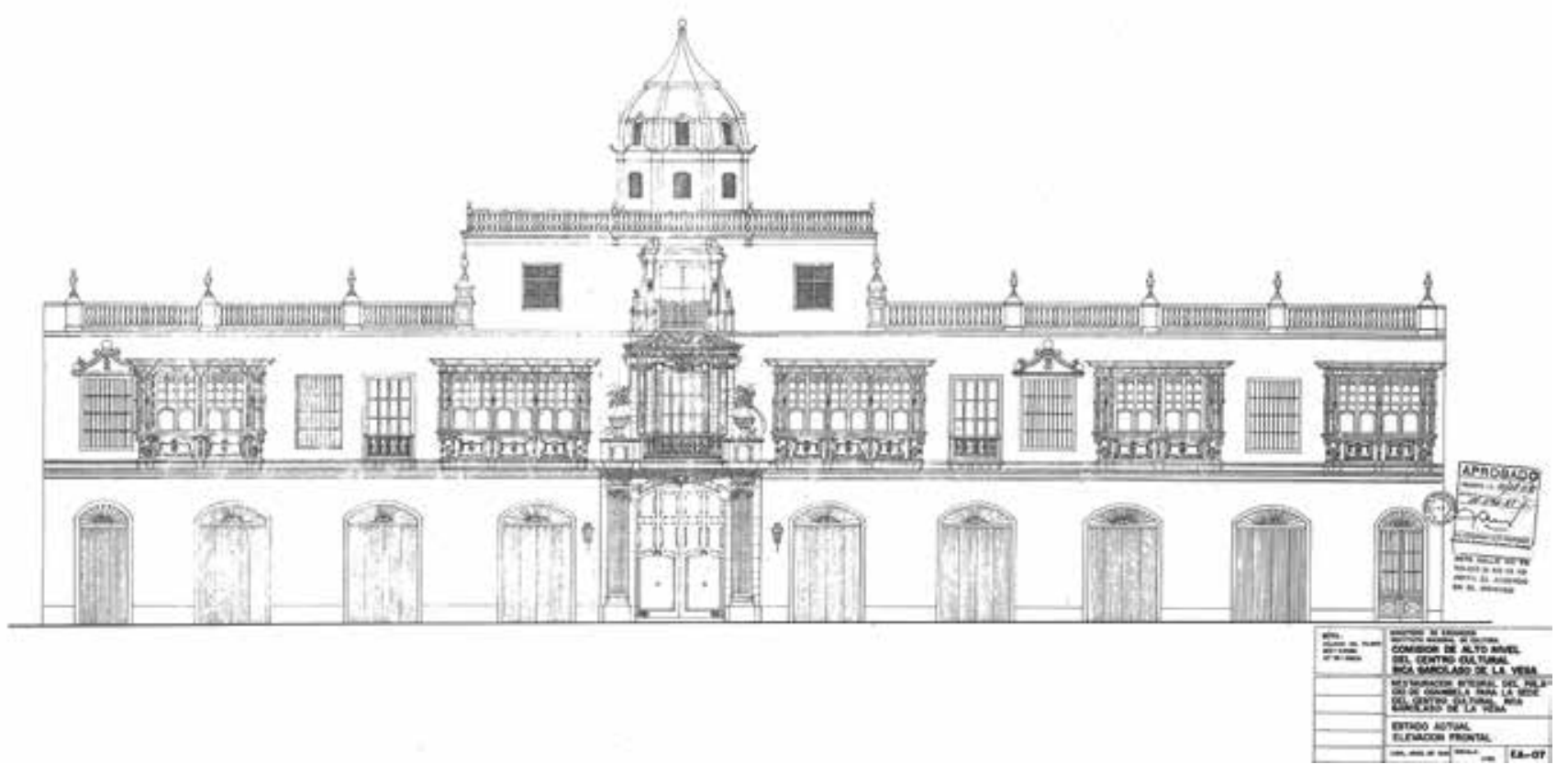

contrada por la arqueóloga Isabel Flores durante el diagnóstico arqueológico realizado como parte del Proyecto Integral de Restauración de 1981.

Las excavaciones arqueológicas evidenciaron que, en la primera etapa de la época colonial, el área que ocupaba la casa era un huerto donde posteriormente se construyó uno de los claustros del convento de Santo Domingo. Este, caracterizado por contar con una sola planta rústica, poseía canales de acequias de uso interno, construidas con ladrillo, y un estanque en el patio central. En una segunda etapa de la época colonial, luego del desastroso terremoto de 1746, Martín de Osambela adquirió el lugar y construyó la casa en 1790, que recién sería ocupada en 1806 (Flores, 1988) (Figura 1).

Cuando fue construido, el edificio era el único de más de dos plantas. Contaba con una hermosa fachada, una tercera planta breve central sobre la portada y un mirador con cúpula peraltada, para que don Osambela pueda observar los barcos que llegaban al puerto del Callao. Durante su ocupación, se reutilizaron ambientes existentes, y se construyó el zaguán de la casa, compuesto de lajas y ladrillos. El piso en los ambientes era de ladrillo, madera o azulejos, el primer patio empedrado, y el estanque fue clausurado. El nivel de los canales fue elevado y se cambió la tubería a cerámicas impermeabilizadas con vidriado interno; los tubos en la primera planta fueron empotrados en canales existentes, y en la segunda dentro de los muros (Flores, 1988) (Figura 2).

La esencia de su construcción fue de estilo barroco (época de Martín de Osambela) y posteriormente neoclásica (época de Rebeca de Oquendo). Como menciona César Pacheco: "La casa de Osambela luce la fachada más amplia, elegante y presuntuosa de toda la ciudad colonial y republicana, hasta la construcción de los grandes edificios públicos de la década del 70" (1984, p. 201). El autor afirma que, por estas notables características arquitectónicas, durante un tiempo albergó al libertador don José de San Martín cuando llegó a Lima (Figuras 3 y 4).

Osambela falleció en la Fortaleza del Real Felipe del Callao, donde se refugió en épocas de Rodil y Campillo. La viuda y los hijos de Osambela perdieron la posesión del inmueble en 1837, como consecuencia de un juicio por deudas que favoreció a María Meza.
Figura 2. Plano de estado actual a escala $1 / 50$ de la fachada principal de la Casa de Osambela presentado al Instituto Nacional de Cultura. En Proyecto integral de restauración del Palacio de Osambela (Tomo I-A), por Comisión de alto nivel del Centro Cultural Inca Garcilaso de la Vega [CANCCCIGV], Lima, 1981. 
devenir Vol. 5, N9, ENERO - JUNIO 2018, PP. 77-98 - ESTUDIOS | ISSN 2312-7562 | E-ISSN 2616-4949

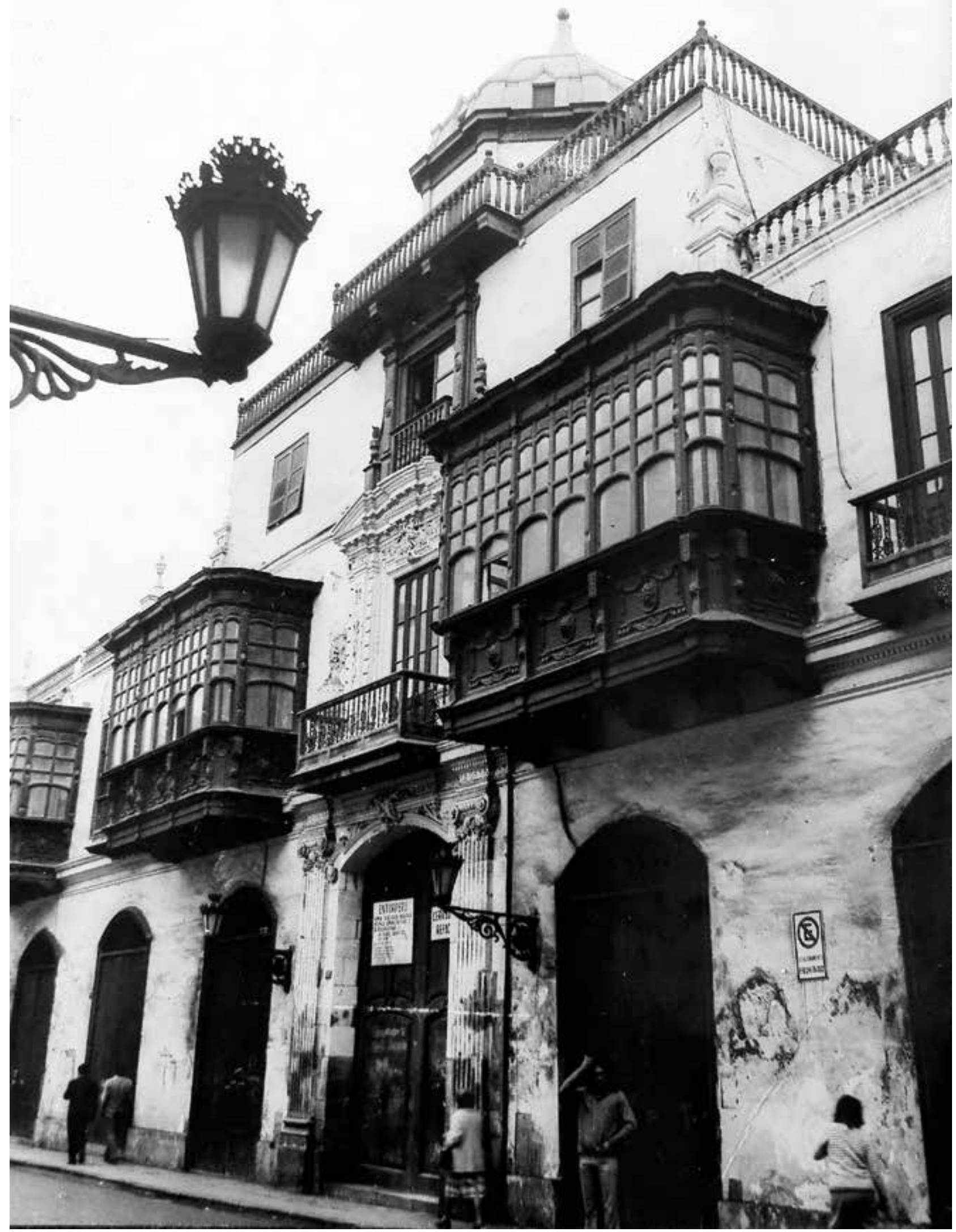


Después fue vendida, y la compraría José de la Asunción Oquendo en 1854, cuya hija fue la última propietaria antes de que pase a ser propiedad de la Caja de Ahorros de Lima, en el año 1941. Luego esta institución alquilaría la casa a las oficinas de ENTURPERU, empresa que la ocuparía desde 1968 hasta el año 1974, año en que acontece un terremoto muy fuerte, tras lo cual quedó desocupada hasta su segunda restauración (Proyecto Integral de Restauración del Palacio de Osambela y su Adecuación para la Sede del Centro Cultural: Inca Garcilaso de la Vega, 1981).

En cuanto a restauraciones anteriores a 1981, la Casa de Osambela fue intervenida en 1964 por don Héctor Velarde y Víctor Pimentel, y fungió como sede de la Corporación Nacional de Turismo en tiempos de Benjamín Roca Muelle y Miguel Mujica Gallo. Luego se suscitaron dos terremotos, en 1966 y 1974 respectivamente, por lo que se inició, a finales de los años 70, un programa de restauración que no fue concluido (Pacheco, 1985).
Figura 3. Fachada de la Casa de Osambela, que muestra la riqueza de diseños en su paramento. En Proyecto Integral de Restauración de Palacio de Osambela (Tomo I-B), por CANCCCIGV, Lima, 1981

Figura 4. Detalles en la fachada de la Casa de Osambela, que muestran los trabajos en piedra y estuco sobre el ladrillo (a, b y c), y la decoración en madera en los balcones de cajón (d). En Proyecto Integral de Restauración de Palacio de Osambela (Tomo I-B), por CANCCCIGV, Lima, 1981
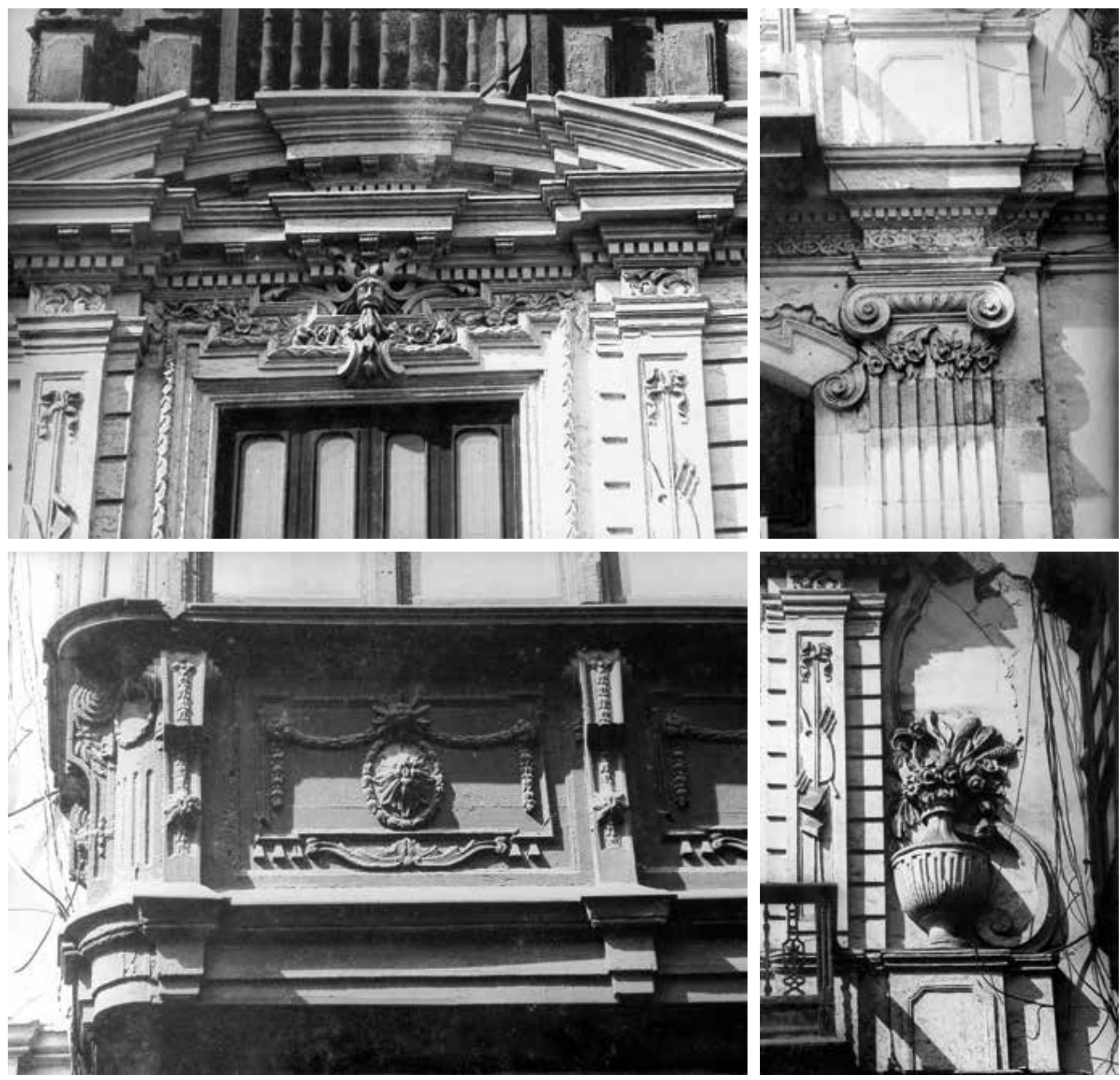
En cuanto a la restauración integral objeto de este análisis, esta surgió como iniciativa del Patronato del Colegio Mayor de San Martín de Porras, que en el año 1979 decidió invertir sus fondos en la adquisición, restauración y equipamiento de una casona virreinal limeña, para convertirla en sede de una institución dedicada a estudios culturales peruanos. Así, este espacio albergó a numerosas instituciones:

- Academia Peruana de la Lengua

- Academia Nacional de la Historia

- Oficina de Educación Iberoamericana

- Instituto Peruano de Cultura Hispánica

- Patronato del Colegio Mayor de San Martín de Porras

- Asociación Hispano-Peruana de Profesionales

- Comisión Mixta Peruano-Española de Intercambio Cultural

El 28 de enero de 1981, el Instituto Nacional de Cultura (INC) aprobó la solicitud para la restauración integral del inmueble, con Acuerdo No 13/28.1.81 e Informe 039-80-DTCPMC. Se otorgó la autorización para el inicio de las obras el 27 de noviembre de 1981, mediante Acuerdo Nº1/27.11.81.

En enero de 1982, se realizó un convenio entre el Patronato del Colegio Mayor de San Martín de Porras, el Banco Central Hipotecario y el Ministerio de Educación, para asumir la responsabilidad económica y administrativa de la restauración integral de la Casa de Osambela (Pacheco, 1985). El Gobierno español, a través de un programa de ayuda técnica, entabla en 1981 junto con un grupo de profesionales peruanos una Comisión de Alto Nivel del Centro Cultural Inca Garcilaso de la Vega, que sería la responsable de la conducción y desarrollo del Proyecto Integral de Restauración del Palacio de Osambela y su Adecuación para la Sede del Centro Cultural Inca Garcilaso de la Vega.

Por parte del Gobierno español, se contó con el apoyo del Arq. Ignacio Garate Rojas, restaurador y funcionario del Ministerio de Cultura de España, y autor del anteproyecto de restauración de la Casa de Osambela. Este anteproyecto fue desarrollado por un equipo de profesionales peruanos bajo la coordinación del Arq. José Niño Villegas y la supervisión del Arq. Víctor Pimentel. Intervino también en la primera etapa de la obra el Arq. Luis Felipe Calle y Calle. Los trabajos de investigación arqueológica estuvieron a cargo de la Lic. Isabel Flores Espinosa, Rubén García Soto y Lorenzo Huertas, cuyos hallazgos contribuyeron a obtener información histórica del sitio y el material recuperado que se exhibe en el museo de sitio instalado en la planta baja de la casona (Pacheco, 1985).

La obra demandó un tiempo de 18 meses de trabajo. desde octubre de 1981 a marzo de 1983, y empleó un presupuesto de 186 millones de soles.

\section{Marco teórico}

En el Proyecto Integral de Restauración del Palacio de Osambela y su Adecuación para la Sede del Centro Cultural: Inca Garcilaso de la Vega no se mencionan las normativas y bases teóricas de la restauración llevada a cabo el año 1981. Sin embargo, sí se mencionan los criterios básicos de restauración, que aquí se analizarán en relación a los postulados de restauración de la época, como los principios de la Carta de Venecia (1964) y la Carta de Restauro de 1972 (1990).

También se realizará el análisis de adecuación a nuevos usos del edificio, considerando para ello los criterios planteados por Evelyn Patiño (2010) para la evaluación y asignación de nuevos usos en los inmuebles patrimoniales en su artículo"La Refuncionalización de Bienes Inmuebles Patrimoniales: Criterios para Asignar la Función". El planteamiento 
de estos criterios busca ayudar a determinar los aspectos que deben considerarse al intervenir un bien inmueble patrimonial, dejando de lado el subjetivismo de los gestores o restauradores. Estos criterios abordan aspectos sociales, espaciales, funcionales y económicos, que permitan el uso adecuado, y la vigencia del inmueble a través de la integración con su entorno y la apropiación por parte de la comunidad.

Antes de establecer el marco conceptual de los criterios de evaluación, Patiño (2010) señala que, por lo general, los proyectos de conservación del patrimonio inmueble han seguido el siguiente proceso metodológico: identificación, valoración, difusión y restauración. Además, señala que la restauración se centra por lo general en la recuperación de la forma física material de la edificación, con lo que se resta importancia a la funcionalidad para la cual se restaura el inmueble. Ante dicha situación, propone un cambio en cuanto al último proceso, e introduce como método de conservación del patrimonio inmueble la intervención, concepto más amplio que define como "todas aquellas acciones enfocadas a restituir una edificación deteriorada a su estado original, tanto en su parte material física como en la funcional, que mantenga el control y equilibrio en ambos aspectos para llevar a cabo el objetivo" (p. 42). Por lo tanto, en una intervención se debe considerar dos aspectos: la adecuación funcional (método) y la restauración (tratamiento).

La adecuación funcional emplea como métodos la función original, que se refiere a mantener la función para la cual fue construida la edificación; el reciclaje, que implica convertir o modificar la estructura para funciones similares o iguales; la rehabilitación, que se refiere a la optimización de espacios sin cambiar las funciones imperantes y el estilo de vida del entorno; y la refuncionalización, que comprende volver a poner en funcionamiento un bien cultural, considerando el cambio de actividades, y funciones arquitectónicas y urbanísticas (Patiño, 2010).

Evelyn Patiño (2010) centra su investigación en "diferenciar los conceptos empleados actualmente y definir la refuncionalización como el termino más apropiado a utilizar, para llevar a cabo el cambio de función en bienes patrimoniales" (p. 50). Por ello, establece una serie de criterios para evaluar los bienes patrimoniales refuncionalizados, así como otra serie para la asignación de nuevos usos. Para fines del presente análisis se privilegiarán los criterios de evaluación para bienes patrimoniales refuncionalizados.

Al respecto, la autora señala que se debe considerar cinco aspectos: la compatibilidad, que es la concordancia entre la función asignada y la función original, que debe permitir los valores excepcionales del bien patrimonial; la transformación, que se refiere a la influencia de la función asignada con relación a su entorno inmediato; la usabilidad, que comprende la capacidad de comprensión y aprovechamiento del usuario frente a la nueva función asignada al bien patrimonial; la participación, que mide el grado de injerencia de los organismos gestores (comunidad, propietarios e instituciones legales) en las decisiones y acciones que afectan la refuncionalización del inmueble patrimonial; y la sostenibilidad, la capacidad que la nueva función brinda al bien inmueble de generar recursos económicos, sociales y culturales para su sostenimiento (Patiño, 2010).

En el caso de la Casa de Osambela, podría decirse entonces que se llevó a cabo una refuncionalización, que consideró el cambio de función del edificio originalmente construido para uso habitacional o de vivienda, y que con la restauración integral se adecuaría para cumplir la función de centro cultural.

\section{Objetivo}

El análisis crítico tiene como objetivo develar qué carácter tuvo la restauración de la Casa de Osambela realizada en 1981, mediante la exposición de sus características arquitectónicas, estructurales, artísticas e históricas; identificando los aportes metodológicos y técnicos que pudieron realizarse en la restauración; observando cuáles fueron 
los puntos débiles de esta intervención, así como la causa de los mismos; y, finalmente, definiendo los criterios teóricos que guiaron la restauración y cómo ello aportó a la adecuada conservación del inmueble.

Asimismo, el análisis de la refuncionalización o adecuación del nuevo uso de la Casa de Osambela permite conocer los aspectos considerados para la revaloración del monumento, y cómo ello contribuyó a la generación de vínculos entre el edificio y su entorno.

\section{Análisis de la intervención}

El objetivo central del proyecto comprendió la restauración integral de la Casa de Osambela y la adecuación del espacio como Centro Cultural Inca Garcilaso de la Vega. También se consideraron otros objetivos, como la salvaguarda de los valores fundamentales del monumento, la autenticidad de sus sistemas y materiales, la recuperación de los elementos arquitectónicos y de otra índole con fines de conservación y restauración, y la recuperación histórica, de fases de construcción y técnicas empleadas para adecuarlos a los nuevos usos.

Para el desarrollo del proyecto de restauración, la intervención se conceptualizó en dos niveles: la restauración y la revitalización. La finalidad del primero fue consolidar o completar los elementos morfológicos deteriorados para poder analizar como una unidad histórico-artística al monumento, procurando alterar lo menos posible su morfología original. El segundo estaba orientado a crear y adecuar los espacios necesarios para los nuevos usos, pero sin perder la significación histórico-artística del monumento, lo que obliga a una modificación parcial de su estructura (Garate, 1980).

Un concepto muy importante que se rescata de los objetivos y que rige la conceptualización de la restauración es el de salvaguarda del monumento. Este concepto también ocupa un lugar importante en la Carta de Venecia (1964) y la Carta de Restauro de 1972. En la primera se señala que "La conservación y restauración de monumentos tiende a salvaguardar tanto la obra de arte como el testimonio histórico" (art. 3, p. 2), mientras que aparece también entre los fines señalados en la Carta de Restauro de 1972 la salvaguarda y restauración de monumentos:

Se entiende por salvaguardia cualquier medida conservadora que no implique la intervención directa sobre la obra; se entiende por restauración cualquier intervención encaminada a mantener vigente, a facilitar la lectura y transmitir íntegramente al futuro las obras de arte y los objetos definidos en los artículos precedentes. (art.4, p. 3)

En cuanto a los criterios generales de restauración que han regido la ejecución del proyecto de restauración de la Casa de Osambela, estos se articulan de la siguiente manera:

- Restablecer los valores esenciales del monumento, adaptándolo sin grandes modificaciones a los nuevos usos.

- Tener presente los principios de sensibilidad-realidad. Se apuesta por una intervención realista sin desvirtuar la esencia del edificio, renunciando a criterios puristas de técnicas obsoletas que no correspondan a la realidad constructiva del edificio y que puedan generar un obstáculo para su ejecución.

- Orientar el estudio analítico del estado antes de la intervención a exaltar los valores testimoniales de su heredad cultural, más allá del simple cuidado de su apariencia externa, sin llegar al uso de técnicas puristas. Por ello se conservó inteligible, no las piezas del edificio, que desde luego son perecederas, sino el mensaje inteligente del manejo de sus formas y procedimientos (Garate, 1980).

En la Carta de Venecia (1964), la base de la formulación de estos criterios, se menciona que "cuando las técnicas tradicionales se muestran inadecuadas, la consolidación de 
un monumento puede ser asegurada valiéndose de todas las técnicas modernas de conservación y de construcción cuya eficacia haya sido demostrada con bases científicas y garantizada por la experiencia" (art. 10, p. 3).

Además, se resalta la importancia de los estudios históricos del monumento para la restauración: “La restauración es una operación que debe tener un carácter excepcional. Tiene como fin conservar y revelar los valores estéticos e históricos del monumento y se fundamenta en el respeto a la esencia antigua y a los documentos auténticos" (art. 9, p. 2). Por lo tanto, los estudios arqueológicos e históricos deberán preceder siempre cualquier intervención de restauración en los monumentos.

En los lineamientos de restauración que guiaron el desarrollo técnico del proyecto de restauración de la Casa de Osambela se contempló lo siguiente:

- Los materiales modernos que sustituyen a los originales se emplearon en casos en que se requería su uso para mejorar la estabilidad estructural. En algunos casos se complementaron con materiales tradicionales que fueron restaurados y podían aprovecharse.

- En la expresión de elementos decorativos, se empleó materiales y tonalidades semejantes, pero sin tratar de imitar la pátina. La restauración se llevó a cabo con elementos de diseño y color neutral, sin ningún tipo de decoración.

- Se buscó ocultar los elementos nuevos que contrastan con el estado original del monumento, para integrar armónicamente lo nuevo con lo antiguo.

Estos lineamientos concuerdan con lo mencionado en el Art. 7 de la Carta de Restauro de 1972, donde se señala que son admitidas las modificaciones y nuevas inserciones con fines estáticos, siempre y cuando su aspecto no altere la superficie. Concuerda con el respeto de la pátina, y la integración de los elementos nuevos con lo antiguo. En esencia, las mismas directrices también son mencionadas en la Carta de Venecia.

Establecidos los criterios teóricos y metodológicos que guiaran la intervención restaurativa de la Casa de Osambela, el desarrollo del proyecto se plantea de acuerdo con la siguiente estructura:

A) Reconocimiento del estado actual

A.1 Plano de levantamiento del estado actual y levantamientos fotográficos testimoniales

A.2 Análisis estructural del edificio

A.3 Inventario de deterioros (por ambientes y componentes)

A.4 Análisis de sistemas y materiales

A.5 Identificación de causas de deterioro

A.6 Prospecciones arqueológicas

A.7 Estudios históricos

A.8 Estudios artísticos

B) Proyecto de restauración y adecuación a nuevos usos

B.1 Proyecto arquitectónico

B.2 Propuesta de restauración por ambientes

B.3 Proyecto estructural

B.4 Proyecto de instalaciones eléctricas

B.5 Proyecto de instalaciones sanitarias

B.6 Especificaciones técnicas y constructivas

B.7 Metrados, costos y cronograma de obra 

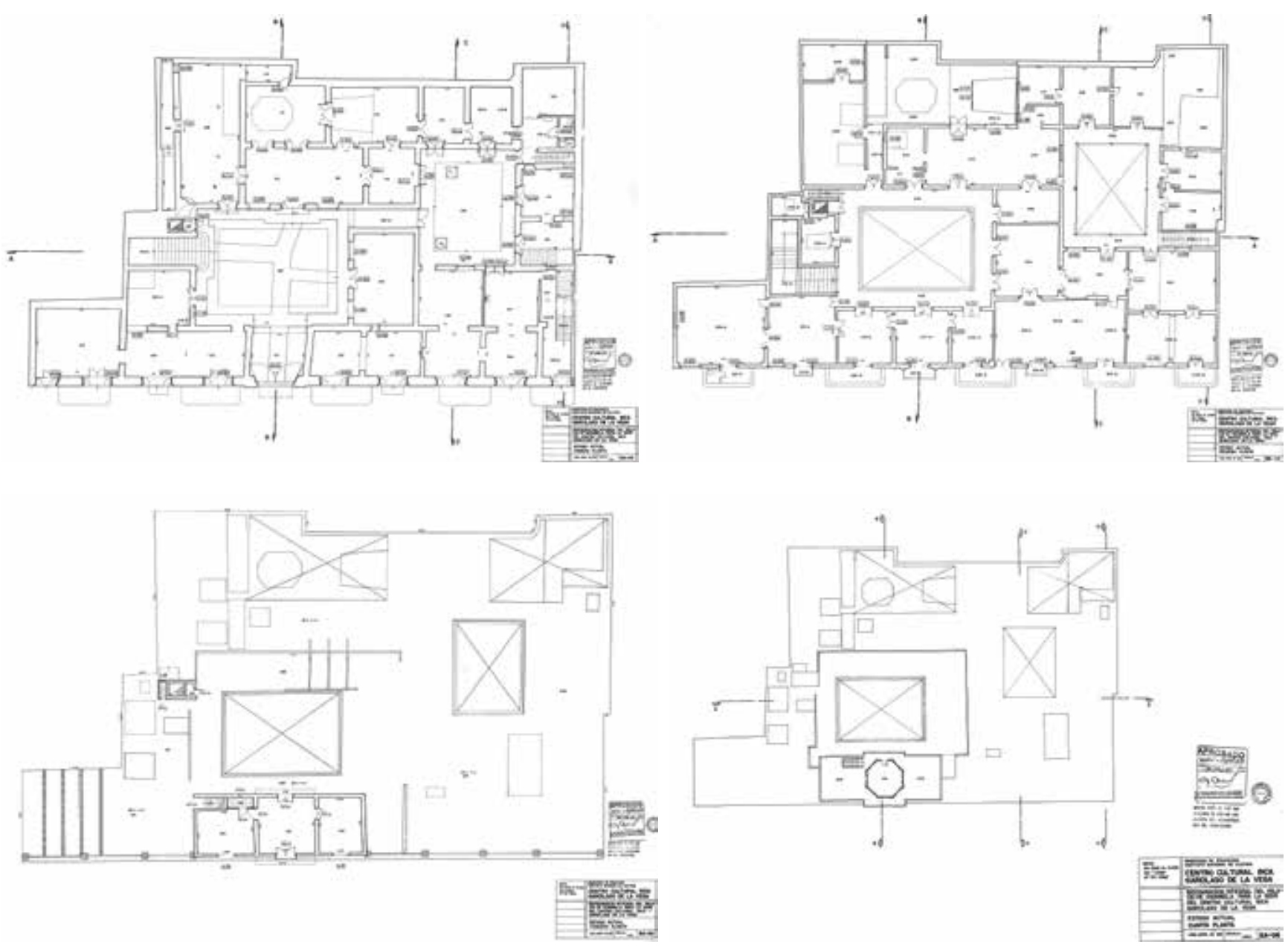

Figura 5. Planos del estado actual de la primera, segunda, tercera y cuarta planta (ordenadas de arriba a abajo e izquierda a derecha) de la Casa de Osambela, presentados al INC, escala 1/50, abril de 1981. En Proyecto Integral de Restauración del Palacio de Osambela (Tomo I-A), por CANCCCIGV, Lima, 1981.
La ejecución del proyecto de restauración de la Casa de Osambela siguió una rigurosa estrategia de intervención. Se llevó a cabo primero un reconocimiento integral del estado actual del inmueble antes de la intervención. Luego, se codificaron todos los ambientes del edificio y se asignó la distribución de los ambientes destinados a un nuevo uso, los cuales debían integrarse armónicamente con el edificio procurando las mínimas modificaciones en su estado actual (1981). Por último, para el desarrollo del proyecto de restauración integral, se planteó primero los criterios de generales de conservación, y los lineamientos generales de restauración y adecuación, para luego llevar a cabo la restauración arquitectónica y estructural del edificio, junto con las implementaciones de instalaciones eléctricas y sanitarias necesarias para la adecuación a su nuevo uso.

Los "Planos de Levantamiento del Estado Actual" fueron realizados por la Comisión de Alto Nivel del Centro Cultural Inca Garcilaso de la Vega, sobre la base de planos, y documentos elaborados por la Junta Deliberante Metropolitana de Monumentos y el Instituto Nacional de Cultura (Figura 5).

En el "Análisis Estructural" destaca la información sobre los materiales empleados en la Casa de Osambela, que corresponden a la construcción típica limeña de la época. Se identificaron muros de adobe o tapia alternados con ladrillos en la planta baja, y muros alternados con quincha en la segunda planta, todos con techos de madera. Presenta cimientos en cantos rodados, compactados con tierra seca. Los muros en la parte posterior de la casa eran de adobe y contaban con escasos sobrecimientos. En la 
201-A

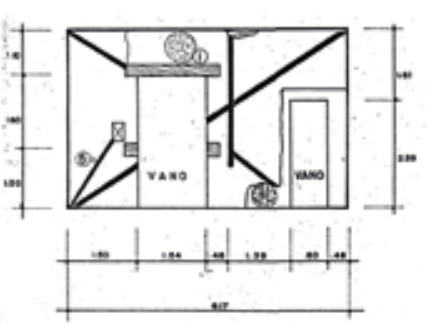

$201-8$

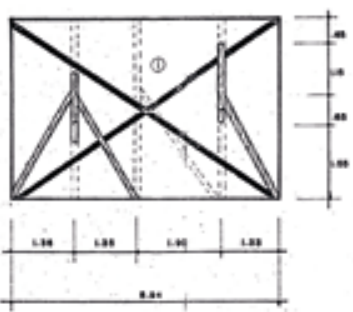

$201-\mathrm{C}$
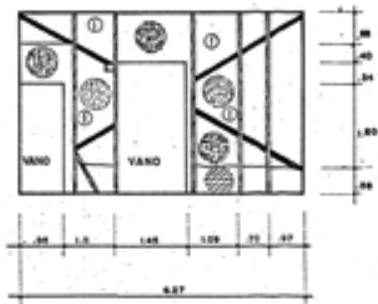

$201=0$

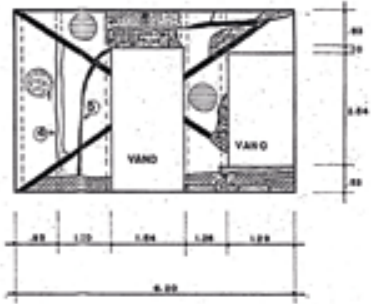

202-A
202-8

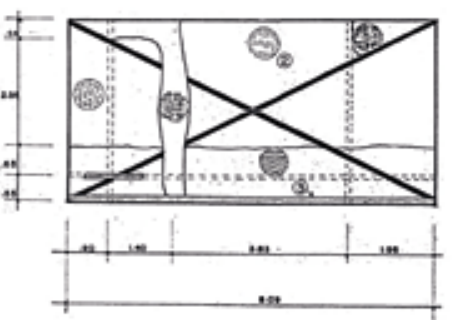

$202-C$

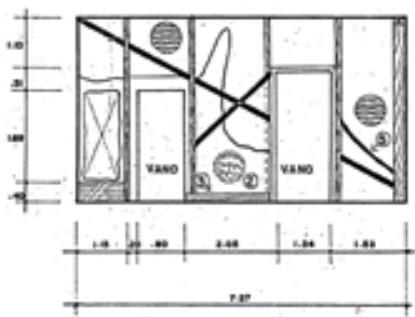

202-0-

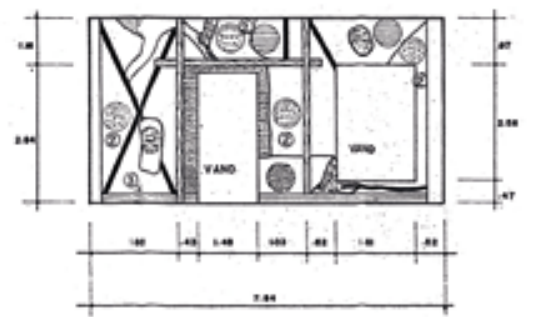

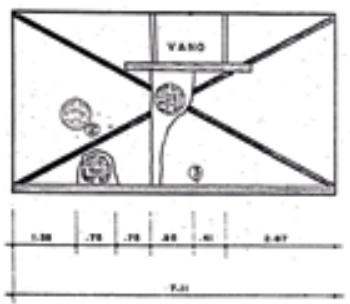

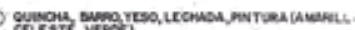

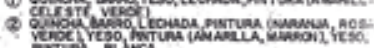
Ning of

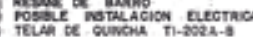

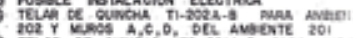

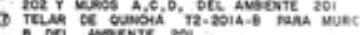
posponción chrocesta fachada, los muros son de ladrillo (90 cm de espesor), mientras que, en la parte posterior, cerca al patio menor, son de adobe (60-90 cm de espesor). Las maderas de suelos y artesanados, en mal estado de conservación, generaban pérdida estructural. Los balcones conforman voladizos, no son la prolongación de las vigas internas, y presentan un empotramiento defectuoso.

Este análisis permitió percatarse de que la disposición estructural del proyecto planteado prevé una posible total sustitución. Este proceso fue crucial para identificar qué elementos podían ser aprovechados y restaurados, y cuáles debían ser sustituidos.

En el "Análisis de Sistemas y Materiales", se resalta la importancia del conocimiento de la estructura física original, no solo para rescatar los valores de autenticidad del monumento, sino para preservar el mensaje de habilidad y conocimiento que se encuentra en su composición, y que le ha permitido lograr una estabilidad y perdurabilidad en el tiempo.

Este análisis se caracterizó por la realización de un estudio cronológico para el mejor entendimiento de su evolución.

a) Ocupación virreinal: De esta etapa debe rescatarse el uso en cimentaciones, y consolidación de pisos y fundaciones, la eficiente tecnología del manejo granulométrico de diferentes tamaños de partículas, lo que le dota de una mejor resistencia y permite una menor dispersión del suelo al ser atacado por la humedad.

b) Primera ocupación virreinal: En esta época se construyeron cimientos, muros y pisos que tienen como característica principal su completa falta de ortogonalidad con la calle, cualidad que preservan las estructuras del edificio actual. Esta diferente orientación se presenta en varias ocupaciones virreinales, lo cual denota su trazo previo al conocido damero de Pizarro.

c) Segunda ocupación virreinal: Se llevó a cabo la edificación de la Casa de Osambela, aprovechando parcialmente algunas estructuras de la primera ocupación virreinal. Se ha identificado tres etapas de edificación en esta ocupación:
Figura 6. Levantamiento y dibujo de inventario de deterioro por ambientes. En Proyecto Integral de Restauración del Palacio de Osambela (Tomo II), por CANCCCIGV, Lima, 1981. 


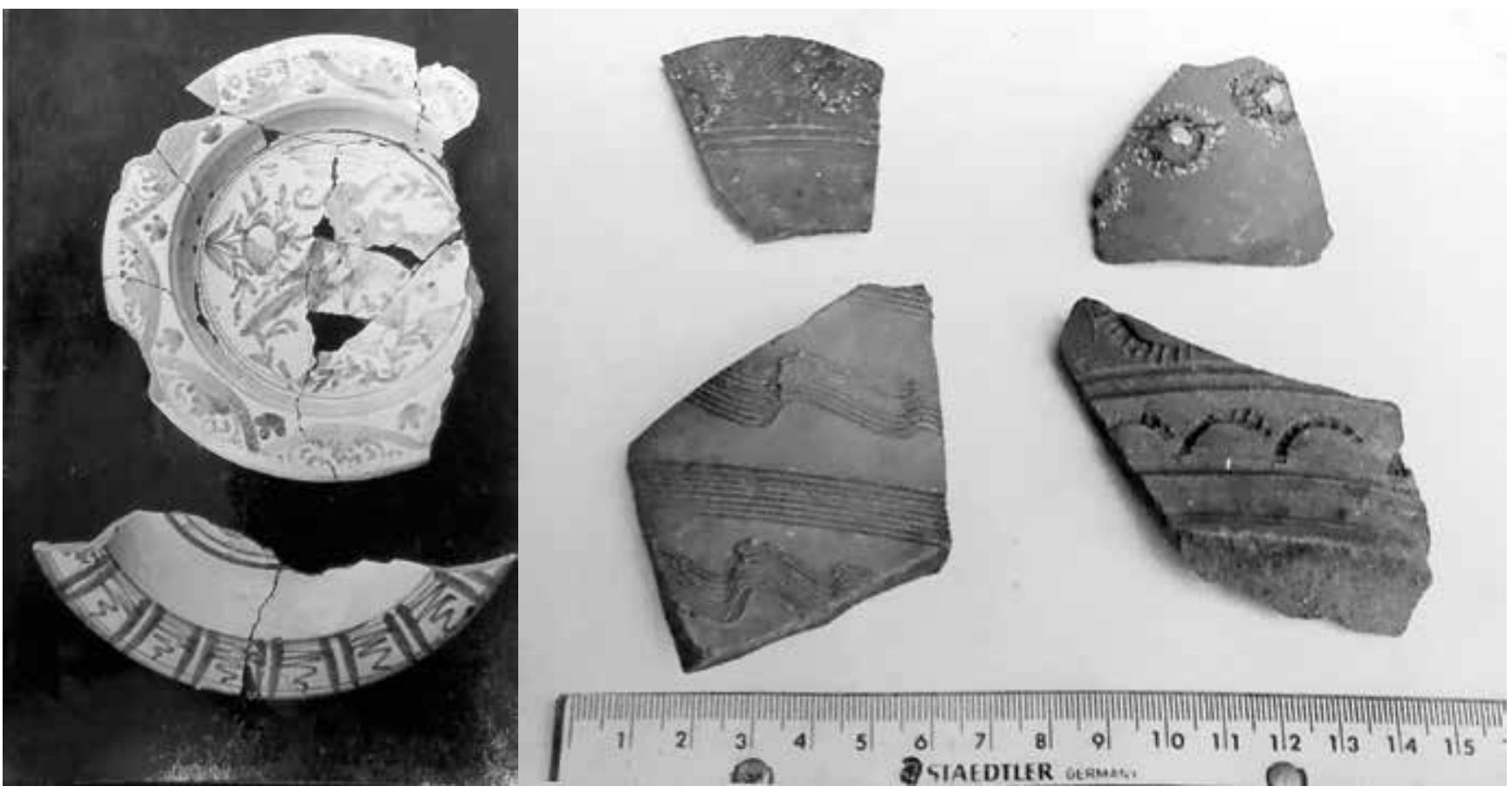

Figura 7. Material arqueológico de la época colonial recuperado en las excavaciones. Plato con decoración de loza limeña (izquierda) y fragmentos de cerámica rojiza torneada (derecha). En Proyecto Integral de Restauración del Palacio de Osambela (Tomo I-B), por CANCCCIGV, Lima, 1981.
- La primera corresponde a la casi totalidad de las dos plantas, de las que quedan paredes de quincha originales. Presentan cimentación de ladrillos grandes con mortero de cal y arena, y sobre ellos está construido un basamento alto de ese mismo material, pero con ladrillos menores. La autenticidad radica en la unidad monolítica de cimientos y sobrecimientos, que forman una retícula continua de aparejo mixto levantado hilada por hilada, que constituye una resistente solera. Los sobrecimientos, de características altas, son cortados por vanos continuos que debilitan naturalmente la solución; por ende, se construyó una arquería de ladrillos para aminorar la carga en los dinteles. Los techos del segundo piso se anclaban a las soleras de los telares portantes, mediante "nabos" y cajuelas que monolitizaban el encuentro de las vigas principales. Sin embargo, la verdadera llave estructural estaba en la ortogonalidad, y el buen ensamble entre los telares portantes de doble bastidor y los telares de amarre de un solo bastidor.

- La segunda corresponde a modificaciones realizadas en los ambientes de la primera etapa y la ampliación de algunas zonas. Se identifica en los cambios en los usos y materiales de sus estructuras, en los que destacan nuevas técnicas de restauración, por lo que no se desarrollan en el proceso del proyecto en análisis.

- La tercera correspondería al replanteo de la fachada y las galerías altas del edificio, donde se construyó el tercer nivel y el mirador. Estas últimas adiciones se han considerado como originales del monumento. Estos cambios permitieron luego, en la restauración de 1981, buscar reforzar el eje que aparece con la construcción del mirador, creando una unidad estilística total, lo cual se consiguió con la modificación de la fachada externa y la opuesta a ella, en el patio principal (Proyecto Integral de Restauración del Palacio de Osambela, 1981, Tomo II).

Se identificaron también en el reconocimiento previo a la restauración “Las Causas de Deterioro". Los factores más agresivos eran la humedad y la presencia de xilófagos. La primera había afectado sobre todo la base de los muros y el suelo; y los segundos, los techos y suelos artesanados. 
Uno de los problemas más difíciles de afrontar fue la humedad; al respecto, el arquitecto José Niño mencionó lo siguiente:

...en el Centro de Lima la napa freática ha bajado mucho, pero existe otra napa freática, que es la de las tuberías rotas, que tiene una NAPA alta y tremenda que baja de los cerros altos, que agrieta todo en el camino, y todas las bases se malogran. (J. Niño, comunicación personal, 8 de noviembre, 2016).

Posiblemente esta es una de las causas del alto grado de humedad. Sin embargo, no se menciona dentro del proyecto alguna medida orientada a aminorar los daños generados por este problema. Solo se menciona una limpieza, la integración de la estructura de acero en el suelo, y la colocación de madera, piedras o laja sobre la superficie (Figura 6).

Con respecto a estos riesgos, la Carta de Venecia (1964) propone que "La conservación de monumentos implica primeramente la constancia en su mantenimiento" (art. 4, p. 2), mientras que la Carta del Restauro de 1972 señala que deben tomarse medidas encaminadas a preservar el bien de las acciones degradantes, de carácter preventivo, para evitar la necesidad de intervenciones de mayor magnitud.

En la "Prospección Arqueológica", se realizaron 12 calas en distintos ambientes de la primera planta de la casa, lo que permitió entender el sistema estructural del monumento, así como las técnicas y procedimientos empleados a través del tiempo de vida del inmueble, y el conocimiento histórico de su ocupación. Se halló evidencia de una ofrenda de la época precolonial; partes de muros de ladrillo y cal, tuberías vidriadas, canales y un estanque de la época colonial l; y cimentación de cantos rodados junto a rellenos de fragmentos de cerámica vidriada y rojiza torneada de la segunda época colonial (Figura 7).

El "Estudio Histórico", también se tomó en cuenta para describir la evolución arquitectónica del monumento, conociendo el contexto histórico social que motivó la construcción del edificio y sus modificaciones. La historiografía testimonial del monumento brinda importante información: no existieron cambios en la volumetría, fachada y patios. Apoyada por un registro fotográfico hallado en una publicación de la revista nacional Ciudad y Campo, de 1928, comprueba la existencia de una bellísima reja de metal fundido en el patio principal, que se encuentra actualmente extraviada; otra publicación, en la revista nacional Mundial del año 1924, comprueba la existencia de rejas en las tiendas de la fachada principal (Proyecto Integral de Restauración del Palacio de Osambela, 1981, Tomo II) (Figura 8).

El "Estudio Artístico" comprendió el análisis de las características artísticas plasmadas en la arquitectura, proceso realizado en conjunto con el análisis arquitectónico. Este se centró en la expresión del color y la decoración en las superficies del monumento, a fin de conseguir, en lo posible, la restitución total o parcial de sus manifestaciones originales. Este estudio permitió conocer que la fachada tuvo un color uniforme, añil azul, mientras que en el interior primó el color rosado.

Sobre el aspecto recién pintado que lucirían los muros, el arquitecto Garate (1980) señaló:

Creemos que la obra de arte no tiene por qué tener el aspecto de abandono a través de siglos para que sea autentico... no tenemos fobia al recién pintado que en definitiva se acerca al estado de origen, otra cosa seria la sistemática eliminación de patinas o disimulo de los naturales desgastes producidos por el paso de los años. (pp. 17-18)

La mayoría de muros evidenciaba decoración mural sobre su color original. Se menciona que "había testimonios de la época de Arts and Crafts; en vez de empapelado, habrían dibujado la administración del papel en los muros" (J. Niño, comunicación personal, 8 de noviembre de 2016) (Figura 9).

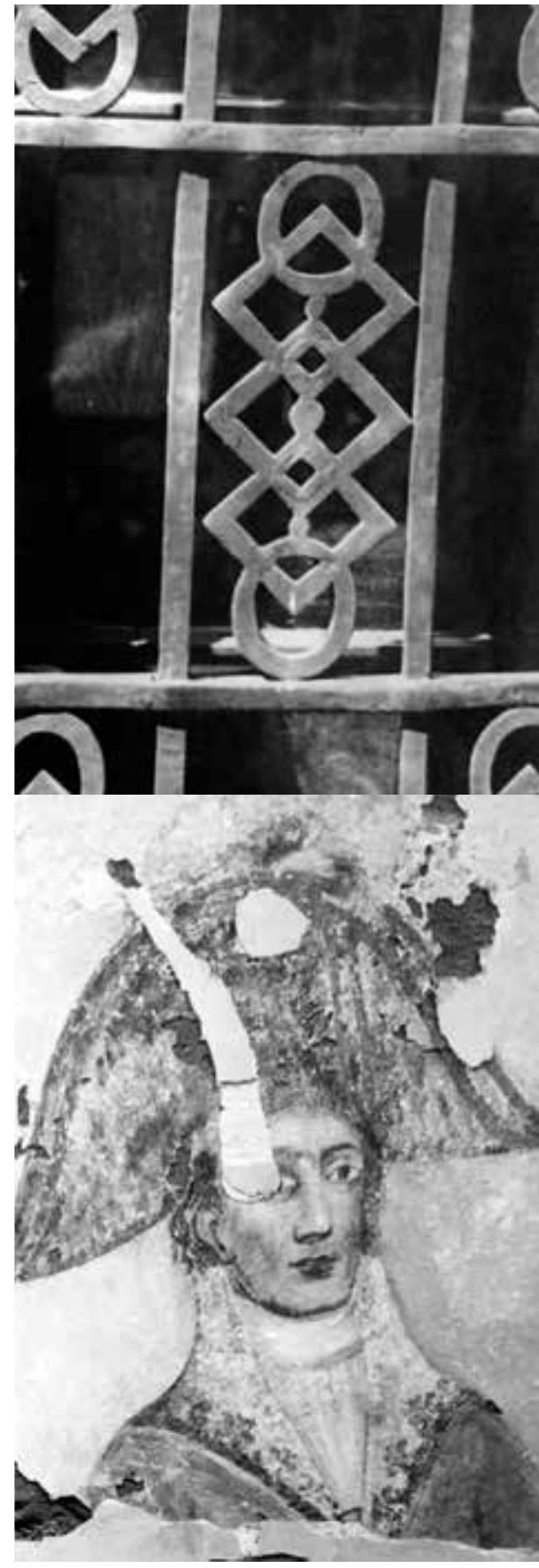

Figura 8. Detalle de reja de bronce extraviada entre 1976 y 1980 . En Proyecto Integral de Restauración del Palacio de Osambela (Tomo I-B), por CANCCCIGV, Lima, 1981.

Figura 9. Detalle de pintura mural en la caja de la escalera principal, pintados directamente sobre la capa de estucado. En Proyecto Integral de Restauración del Palacio de Osambela (Tomo I-B), por CANCCCIGV, Lima, 1981 


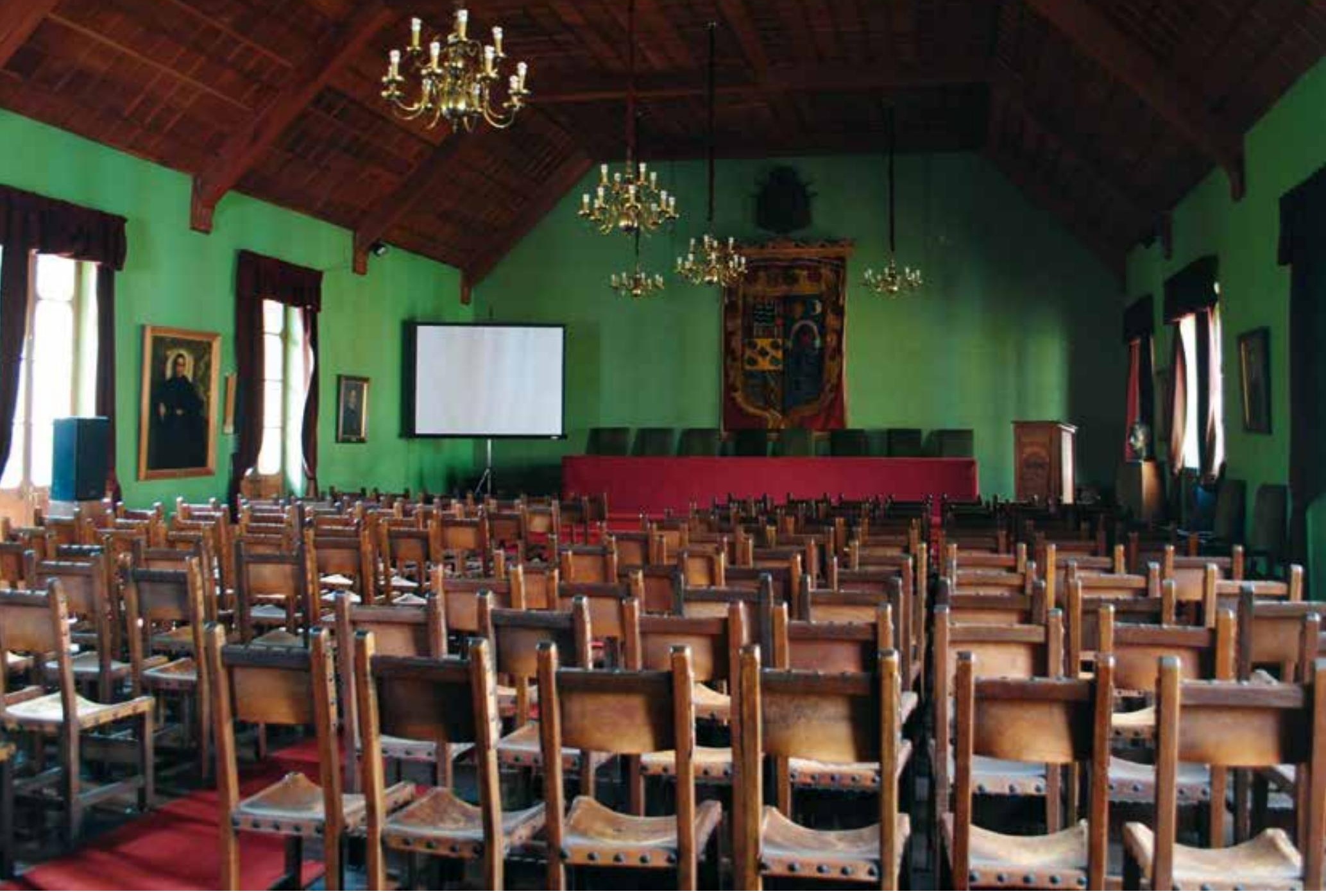

enmarcadas y divididas en el centro ficticiamente, unas ventanas en composición de cuadrados, daba la transparencia que queríamos, daba la seguridad que queríamos, pero no representaba lo que allí pasaba, no tenía una comunión completa... entonces acomodé algunos elementos para que se vean muy unitario, para que los ritmos de la composición del diseño no se perdieran, porque las ventanas mantienen ese ritmo. (comunicación personal, 8 de noviembre de 2016)

Pacheco (1984) menciona que existen registros plásticos, dibujos de la Casa de Osambela elaborados por el francés Leonce Angrand, que corresponderían a la ocupación de sus segundos propietarios, los Oquendo, donde se aprecian puertas que pertenecían a los locales comerciales, por lo que para él estas serían posteriores a las originales.

Para algunos esta variación, el reemplazo de puertas por ventanas, estaría yendo en contra del principio de autenticidad tal como se menciona en la Carta de Restauro de 1972 (1990): "Constituye una exigencia fundamental de la restauración el respetar y salvaguardar la autenticidad de los elementos constructivos" (p. 9).

Sin embargo, el cambio de este elemento arquitectónico probablemente se encuentre sustentado en lo expuesto en el "Anexo D" de la misma carta, donde se hace alusión a las instrucciones de intervención en centros históricos:

Las intervenciones de restauración en los centros históricos tienen la finalidad de garantizar -con medios e instrumentos ordinarios y extraordinarios- la permanencia en el tiempo de los

Figura 11. Sala de conferencias con el techo en forma de artesa. Recuperado en 2015 de http://www.netlima. com/lugar-deta.php?pcamp0=6425. 


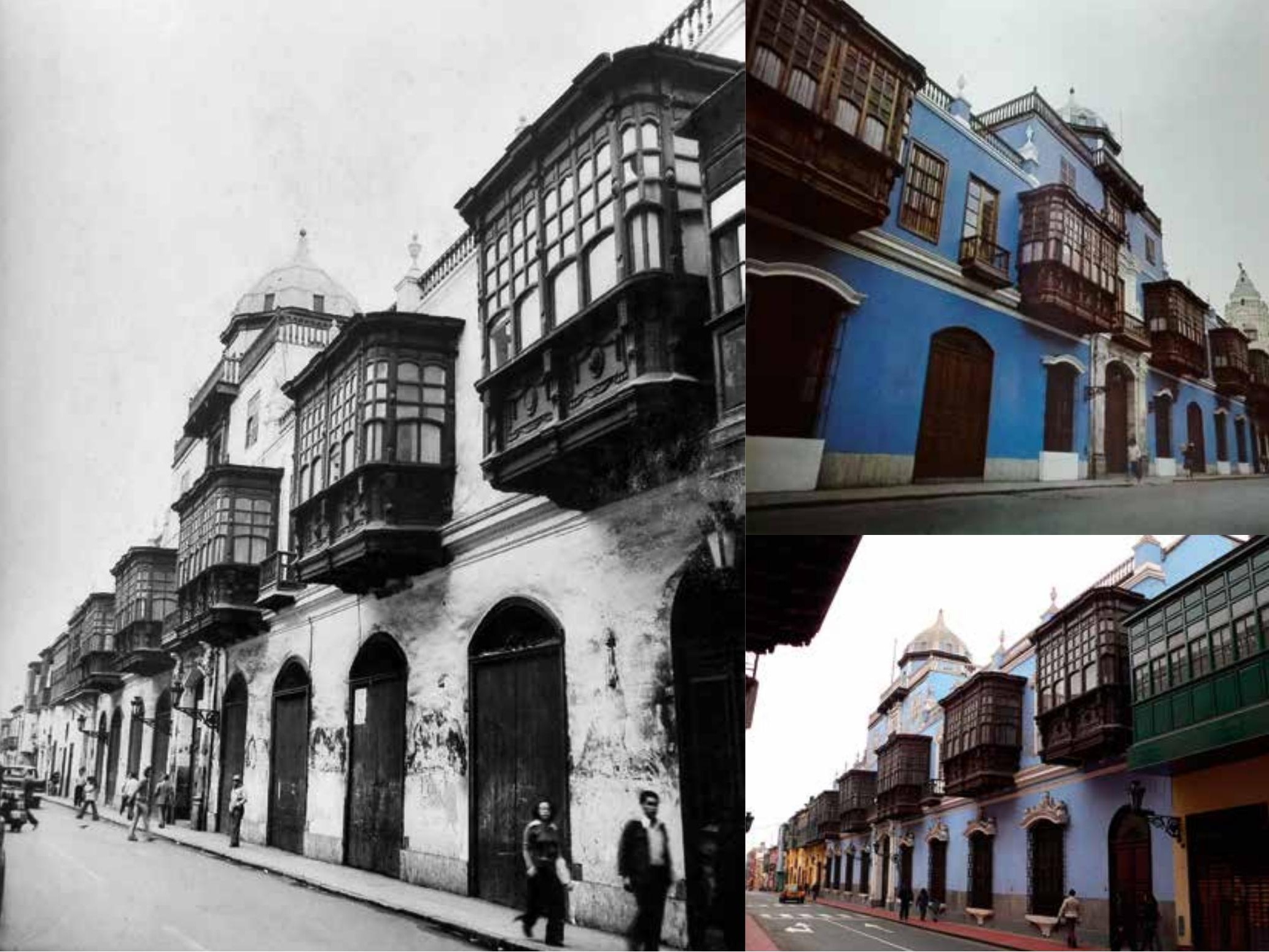

En cuanto al aspecto estructural, el Proyecto de Restauración contempló la restauración de los muros y elementos portantes no como copias, sino con el empleo de materiales modernos que otorgan estabilidad. En algunos casos se realizaron sustituciones por muros de ladrillo con adición de pies derechos metálicos en los cimientos, como en el caso de la Sala de Conferencias.

El arquitecto José Niño indica que se introdujo una novedosa técnica, poco usada en las restauraciones en esa época, el empleo del acero junto al adobe. Al respecto, señala lo siguiente:

Le metimos adentro del muro algo que siempre consideramos pecado, pero se consideraba pecado porque no se había estudiado el caso, que era la sociedad entre el acero y el adobe... el único material que se prestaba era el acero porque uno podía cambiarle la masa al acero fácilmente y mantenerlo integrado, siempre y cuando no produjera un golpeteo. (comunicación personal, 8 de noviembre de 2016)

Por otro lado, los suelos y techos en mal estado se sustituyeron por una estructura básica metálica, apoyada sobre estos para evitar el incremento de cargas, completada con elementos de madera tradicionales o sustituidos por madera de caoba. Algunos se mantuvieron con pino de Oregón, madera por lo general de muy mala calidad. Los pisos, casi inexistentes, fueron reemplazados de acuerdo a la funcionalidad requerida: en los patios se diseñaron enlozados en fajas, alternados con zonas de cantos rodados, todos sobre soleras de hormigón (Figuras 16, 17 y18).
Figura 13. Fachada de Casa de Osambela. Detalle de puertas sin rejas, antes de la intervención. En Proyecto Integral de Restauración del Palacio de Osambela (Tomo I-B), por CANCCCIGV, Lima, 1981

Figura 14. Fachada de Casa de Osambela. Detalle de cambio de puertas a ventanas, después de la intervención. En Memoria y utopía de la vieja Lima, C. Pacheco, p. 185, Lima 1985

Figura 15. Fachada actual de la Casa de Osambela. Manuel González Olachea y Franco. Recuperado en 2007 de https://es.wikipedia.org/wiki/Casa_ de_Osambela 
Los balcones quedaron sostenidos por una especie de jaula metálica, para que se acoplen mejor a la fachada. Por último, los nuevos revoques sobre los muros verticales se realizaron con mortero de yeso-arena sobre fábricas de ladrillo, y se trataron con sistemas tradicionales de tierra, guano natural o agua sobre muros de adobe o tapia.

Igual importancia que la recuperación de los aspectos físicos del monumento, en la restauración, tiene el considerar los criterios y lineamientos que permitan dotar de un adecuado nuevo uso del espacio patrimonial.

En la Carta de Restauro de 1972 (1990), se señala los tipos de intervención que se pueden dar a nivel urbanístico y de edificio que se relacionan a restauraciones con una visión de nuevos usos. Sobre los tipos de intervención a nivel edificio se reconocen dos: las que se realizan para el "saneamiento estático e higiénico" del edificio, donde es de particular importancia el respeto a las cualidades tipológicas, constructivas y funcionales del edificio, y, por otro lado, aquellas que implican la "renovación funcional de los órganos internos", en las que

Es de fundamental importancia el respeto a las cualidades tipológicas y constructivas de los edificios, prohibiendo todas aquellas intervenciones que alteren sus caracteres, así como los vaciamientos de la estructura edilicia o la introducción de funciones que deformen excesivamente el equilibrio tipológico-constructivo del organismo. (p. 17)

La restauración y adecuación a nuevos usos de la Casa de Osambela corresponde a este último tipo de intervención, ya que se le ha asignado una función distinta a la original.

A pesar de que se tomó en cuenta estos postulados, que responden a una mirada más amplia de lo que implica la restauración de un bien inmueble, en el proyecto de restauración integral de la Casa de Osambela no se consideró establecer un componente que evaluara los impactos o alcances a nivel social de la restauración.

Por lo tanto, aquí se evaluará y analizará las incidencias de la nueva función asignada al bien patrimonial, en el entorno y la comunidad asociada, sobre la base de la propuesta de Evelyn Patiño (2010). Esta autora plantea realizar la evaluación de la refuncionalización o adecuación a nuevos usos, en torno a cinco aspectos: compatibilidad, transformación, usabilidad, participación y sostenibilidad.

Sobre la adecuación al nuevo uso como centro cultural, cabe mencionar que, en cuanto a la compatibilidad, el nuevo uso asignado sí es compatible con la función original, pues fue posible mantener las condiciones y el valor excepcional que posee la Casa de Osambela, conservando la mayor parte de sus características originales. Asimismo, la restauración realizada es compatible con la reglamentación vigente que determina los usos adecuados para los monumentos ubicados dentro del Centro Histórico de Lima.

En cuanto al aspecto de transformación, vinculado sobre todo con el entorno del bien patrimonial, el grado de influencia y los efectos de la intervención en él, es posible afirmar que ha sido mínimo. Se ha conservado la identidad, memoria e imagen del entorno: la intervención no ha generado modificaciones que contrasten con el escenario que ocupa el inmueble. El nuevo uso asignado es acorde a las condiciones urbanísticas de la zona: como Centro Cultural dentro de un espacio histórico, contribuye a generar un adecuado ambiente para el público interesado en el enriquecimiento cultural.

Con respecto a la usabilidad, la relación directa entre el espacio físico y el usuario, cómo el primero es aceptado, comprendido y aprovechado por el usuario, cabe mencionar que ha ido cambiando a través del tiempo. La Casa de Osambela, como espacio cultural, cumplía con las exigencias de su época: allí se desarrollaban una serie de eventos culturales, contaba con un pequeño museo de sitio, diversas salas de exposición y auditorios. Actualmente no se desarrollan muchos eventos culturales, y el acceso a sus ambientes está restringido a visitas programadas. 


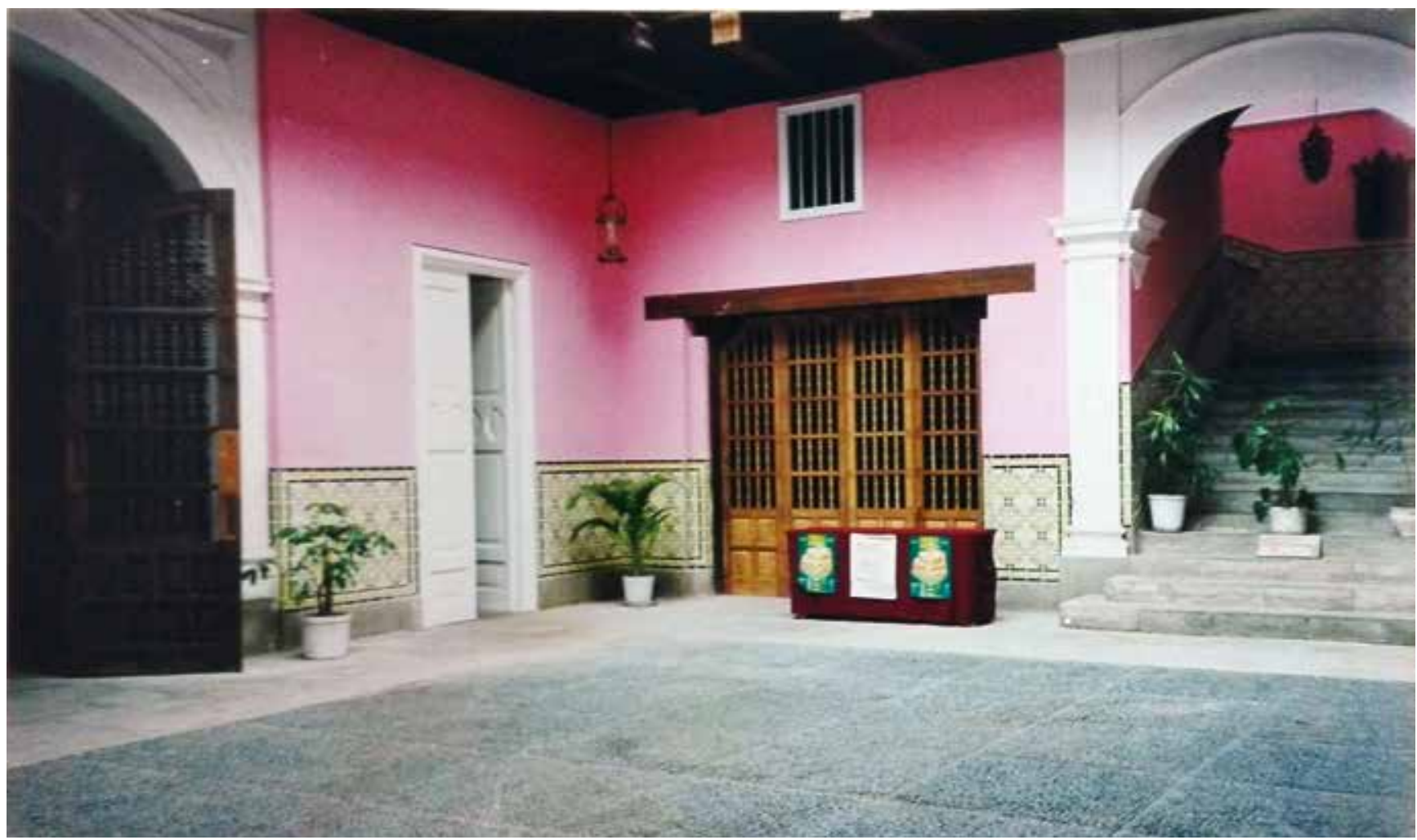

Un aspecto que no fue tomado en cuenta en la toma de decisiones para la asignación de su refuncionalización fue el de la participación. Para realizar la intervención en la Casa de Osambela, la asignación del nuevo uso no fue consultada ni de conocimiento público, sino que fue injerencia de los propietarios, y solo consultada y aprobada por los demás agentes involucrados en la gestión y financiamiento del proyecto, como el INC (hoy Ministerio de Cultura), el Ministerio de Educación, el Gobierno Español y el Banco Interamericano.

En cuanto a la sostenibilidad de la intervención realizada en la Casa de Osambela, su adecuación a centro cultural, puede afirmarse que fue sostenible al inicio. Durante los primeros años de funcionamiento gozaba de una mayor demanda, pues era uno de los más grandes centros culturales y allí se desarrollaban eventos culturales significativos, como la Bienal, por lo que era un espacio muy concurrido. En la actualidad se cuenta con otros espacios, más grandes y mejor adecuados tecnológicamente para este tipo de eventos, por lo que la Casa Osambela ha sido relegada.

Si bien el Centro Cultural Inca Garcilaso de la Vega es una institución sin fines de lucro, se requiere de presupuesto para su mantenimiento. En la actualidad este financiamiento está cubierto por el alquiler de sus espacios a instituciones académicas y educativas como la Real Academia Peruana de la Lengua, la Academia Nacional de la Historia, la Academia Nacional de la Medicina, la Academia Peruana de Derecho, la Academia Nacional de Ciencias, la Academia Peruana de Ingeniería y la Organización de Estados Iberoamericanos.

Cabe mencionar que desde el año 2001 no se han realizado proyectos de restauración o mejoramiento de la infraestructura del edificio. Son el mismo Centro Cultural Inca Garcilaso de la Vega y su titular, el Ministerio de Educación, quienes en conjunto deben velar por la continuidad de sus funciones, su restauración, su puesta en valor y su mantenimiento.
Figura 16. Detalle de acabado del suelo restaurado. En Informe de Intervención tecno arquitectónica para el mantenimiento de la fachada principal e interiores, por Instituto Nacional de Cultura, p. 3, Lima, 1998. 


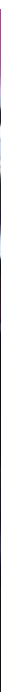

Figura 17. Vista del primer patio al Zaguán, antes (izquierda) y después de la restauración (derecha).

En Proyecto Integral de Restauración del Palacio de Osambela (Tomo I-B), por CANCCCIGV, Lima, 1981; Informe de Intervención Tecno Arquitectónica para el Mantenimiento de la Fachada Principal e Interiores, por Instituto $\mathrm{Na}$ cional de Cultura, p. 3, Lima, 1998.

\section{Conclusiones}

El análisis de la restauración integral de la Casa de Osambela lleva, en primer lugar, a tomar en cuenta el contexto en el que se desarrolló dicha labor. El inmueble, desde su construcción, contó con un notable reconocimiento estético e histórico; el proyecto fue, en la década de los 80 , una de las más ambiciosas intervenciones de restauración realizadas en el Centro Histórico de Lima.

Convertida en Centro Cultural Inca Garcilaso de la Vega, fue inaugurada por el entonces presidente Fernando Belaunde, como homenaje a Lima en su 450 aniversario. Al evento acudieron figuras importantes del ámbito político y social (Pacheco, 1988). Se cree que no fue una intervención que haya padecido apuros económicos, ya que se emplearon los mejores materiales disponibles para los trabajos de restauración.

Parte de la gestión del proyecto recayó en el apoyo técnico brindado por el Gobierno Español, cuyo Ministerio de Cultura designó al arquitecto Garate para que marque las pautas de los criterios y procedimientos a realizar en la restauración, los cuales se plasmarían en la elaboración del anteproyecto, que se desarrolló casi en su totalidad como fue previsto.

En cuanto a la restauración, esta se rigió por principios básicos orientados a garantizar la armonía de los elementos antiguos y los nuevo, ya que se emplearon elementos modernos, como soleras, rejillas de acero, etc. La mayoría de estos elementos se encuentran en la parte estructural del edificio, el cual presentaba inestabilidad, sobre todo en sus elementos portantes.

También se aprecia en los acabados el respeto por los contrastes evidenciados, que han tratado de integrarse. Como se observa en los acabados de pintura, los revoques de los muros o el acabado de las maderas, se usaron los mismos acabados para los materiales modernos y antiguos.

Se buscó preservar la autenticidad histórica, más en un sentido simbólico que en uno material, teniendo en cuenta las características arquitectónicas resaltantes del edificio, como se aprecia en los análisis realizados durante la etapa de reconocimiento del estado actual (1980), que también permitieron el reconocimiento de sistemas y técnicas tradicionales que podrían ser luego empleados, con materiales adecuados y resistentes, modernos o antiguos recuperados. 
preste mayor atención a los criterios de usabilidad, participación y sostenibilidad, tres criterios que guardan estrecha relación con el contexto actual y la comunidad.

Si se considera que la creación arquitectónica no solo se basa en la función y forma, sino también en el espacio, como menciona Patiño (2010), "Lo ideal sería que tanto la forma, como la función y el espacio se pudieran fusionar, de tal manera que existiera un equilibrio entre las tres...Es allí donde verdaderamente aparece el significado de la arquitectura" (p. 25). Por lo tanto, resulta necesario analizar el entorno y adecuar la utilidad del inmueble a las necesidades actuales de los usuarios.

Sin duda, esta crítica lleva a pensar que cada monumento es único en su acontecer histórico y en su creación, por lo que debe considerarse, como parte principal de toda restauración, el conocimiento integral del edificio. Además, se debe tener en cuenta siempre que el edificio se mantiene vivo gracias su uso y valoración, por lo que es importante vincularlo con la sociedad si se desea que este notable edificio mantenga vigente el reconocimiento de los valores patrimoniales que posee.

\section{Referencias}

Capitel, A. (1999). Metamorfosis de monumentos y teorías de la restauración. Madrid, España: Alianza Editorial.

Carta de Restauro de 1972 (1990). Traducción de M. J. Martínez Justicia. Málaga, España: Colegio de Arquitectos de Málaga. Carta de Venecia. (1964). II Congreso Internacional de Arquitectos y Técnicos de Monumentos Históricos, Venecia.

Corporación de Turismo del Perú. (1964). La casa de Osambela o de Oquendo. Lima, Perú: La Corporación.

Flores, I. y García, R. (1981). Investigación arqueológica-histórica de la casa Osambela (o de Oquendo). En Boletín N 14 Centro de Investigación y Restauración de Bienes Monumentales. Lima, Perú: Instituto Nacional de Cultura.

Flores, I. (1988) La arqueología y la restauración de monumentos histórico-artísticos: Estudios de la casa Osambela. En Arquitectura y Arqueología: Pasado y futuro de la construcción en el Perú (pp. 229-237). Chiclayo, Perú: Universidad de Chiclayo.

Gárate, I. (1980). Memoria del Proyecto de restauración y remodelación de Casa Oquendo o Palacio de Osambela en Lima - Perú. Madrid, España: Ministerio de Cultura.

González, I. (1999). Conservación de Bienes Culturales. Teoría, historia, principios y normas. Madrid, España: Cátedra.

Instituto Nacional de Cultura. (1998). Informe de intervención tecno arquitectónica para el mantenimiento de la fachada principal e interiores. Lima, Perú.

Hayakawa, J. (2010). Restauración en Lima: Pasos y contrapasos. Lima, Perú: Universidad San Martín de Porres.

Pacheco, C. (1985). La casa de Martín de Osambela. En Memoria y utopía de la vieja Lima (pp. 183208). Lima, Perú: Universidad del Pacífico.

Patiño, E. (2010). La refuncionalización de bienes inmuebles patrimoniales: criterios para asignar la función. En La gestión del Patrimonio Cultural. Perspectivas de actuación desde la academia. Bogotá, Colombia: Pontificia Universidad Javeriana.

Proyecto Integral de Restauración del Palacio de Osambela y su Adecuación para la Sede del Centro Cultural: Inca Garcilaso de la Vega. (1981). Proyecto de restauración presentado al I.N.C por la Comisión de Alto Nivel del Centro Cultural Inca Garcilaso de la Vega. Lima, Perú: Autor. 